\title{
An Intercultural Approach to Textbook Evaluation: A Case of Top Notch and Summit Series
}

\author{
Maryam Homayounzadeh (Corresponding author) \\ Shiraz University, Iran, Islamic Republic of \\ E-mail: maryamhomayounzadeh@gmail.com \\ Rahman Sahragard \\ Shiraz University, Iran, Islamic Republic of \\ Email: rahman.sahragard@gmail.com
}

Received: 09-07-2014

doi:10.7575/aiac.ijalel.v.4n.1p.198
Accepted: 06-09-2014

Published: 01-01-2015

URL: http://dx.doi.org/10.7575/aiac.ijalel.v.4n.1p.198

\begin{abstract}
This study investigated the representation of sociocultural identities in six textbooks selected from Top Notch and Summit series, to assess their potential to promote intercultural communicative competence in the learners. TingToomey's identity negotiation theory and Scollon and Scollon's (2001) discourse system structure were used to assess the identity representations and the structure of discourses in the books. Identity representations were analyzed in terms of the four primary elements of cultural, ethnic, gender and personal identities, to determine the extent to which the books could foster communication between members of various identity groups. In the analysis of discourse structures, the study investigated primarily the politeness and face strategies used in the conversations and further the particular ideology they perpetuated, as a clue to their potential to promote the learners' pragmatic competence for intercultural communication. Concerning identity representations in the books, different results were found for the two series. Top Notch, addressing beginner to intermediate level students, proved considerate of diversity in the sociocultural identities it presented and providing information about the values of different cultures and the customs and traditions of various nations it tried to set the bases of interculturality within its audience. Summit, on the other hand, addressing higher intermediate and advanced learners, had a unilateral approach in its identity presentations, depicting principally European and American nationalities and the cultural values of individualism typically associated with them. Nevertheless, where the discourse structures in the books were concerned, both the two series were identical in their exclusive focus upon the utilitarian ideology of discourse and its related politeness and face strategies. This was found as a pitfall in the books, limiting the students' range of discursive resources, which they require for successful intercultural communication in different contexts. The study concluded with subsequent recommendations for improving the content of the textbooks as well as some implications for further research.
\end{abstract}

Keywords: Textbook Evaluation, Intercultural competence, Intercultural communication, Culture, Identity, Discourse system, Utilitarianism, Politeness strategies

\section{Introduction}

The intimate association between language and culture poses a significant question for the applied linguists and materials developers to solve: What is the culture that students should acquire along with the language? Response to this question is undoubtedly significant, leastwise as it determines the content of the textbooks used in language classrooms. After all, as Shardakova and Pavlenko (2004) indicate, language textbooks are not a neutral repository of lexico-grammatical items per se, rather they constitute a significant genre, serving to socialize the readers into a particular ideology and worldview. Questions lie in what this worldview should be and how it should be presented to the learners for the intended socialization to take place.

In deciding on the particular culture to be presented in language textbooks, the main guiding factor is undoubtedly the objective underlying language instruction courses, which presumably is the very goal learners are pursuing in acquiring the language. This objective is generally determined according to the global changes that necessitate the knowledge of an international language. When English was used as a tool merely for communication with native speakers of the target language, their cultural values constituted the content of language textbooks. The more inclusive a book was in defining its circle of the sociocultural identities and the more realistically it depicted their values, the more appropriate it was deemed as a means of enhancing the learners' communicative competence (Shardakova \& Pavlenko, 2004;). Such cultural representation, it was assumed, could give the learners a frame of reference to interpret the information in the target language and to empathize with the target people in their communications with them. (Widdowson, 1990; Alptekin, 1993).

Nevertheless, in today's world, where modern technology has removed the walls between nations, competence in communication with native speakers of English is no longer sufficient, when as Cook (2002) indicates, nonnative 
speakers of the language outnumber its native speakers. Intercultural communicative competence (ICC) is the ultimate goal the streamline of language instruction programs seeks nowadays, aiming to promote global ready students (Deardorff, 2004; Byram, 2003). This new objective in language acquisition entails a refinement in the cultural content of the course books to bring about this socialization for the learners. In this regard, Feng and Byram (2002) have suggested that language textbooks provide an authentic representation of the cultural values of both the native and nonnative cultures. However, the question remains of whether cultural information is sufficient for the learners to become competent for intercultural communication. Although intercultural communication (ICC) is a widely discussed issue in the literature, few studies have considered the concept in the content of language textbooks (Feng \& Byram, 2002), which are regarded as the heart of ELT programs (Sheldon, 1988).

Reviewing the various theories on the essence of intercultural communication, the current investigation seeks primarily to identify the kind of socialization the concept entails. The study will go further to consider the realization of culture in Top Notch and Summit series as a sample of popularly used textbooks in EFL classrooms, claiming to prepare the learners for the purpose of intercultural communication. The analysis will not only serve as an evaluation of the stated textbooks, but will also lead to additional insight concerning materials writing and language instruction to promote intercultural competence.

\section{Literature Review}

Intercultural communication is an offspring of today's world where the flows of information, mass media and the rise in migration and tourism have brought into contact diverse cultures and languages. Consentingly, intercultural communication is defined as "the symbolic exchange process whereby individuals from two (or more) cultural communities negotiate shared meanings in an interactive situation (Ting-Toomey, 1998, pp. 16-17). Although straightforward on the surface, when it comes to the empirical investigation of intercultural communication and definition of intercultural communicative competence, studies differ in their ontological conception of what constitutes an instance of intercultural encounter, given the different assumptions they hold about culture and thus culturally different communities. Such assumptions, apparently, have been refined gradually according to the global changes that necessitate intercultural communication in each era. Accordingly, three traditions exist of ICC studies, two of which have been informative for applied linguists in defining ICC competence as a goal for language instruction.

Cultural community, in the early ICC studies, was interpreted as the national, ethnic or gender group with which individuals were affiliated and thus culture was taken as the knowledge system and values shared by the individuals within each bounded unit (Ting-Toomey, 1998; Gudykunst, 2003; Piller, 2007). Any breakdown in intercultural encounters was assumed to result from the distinct socializations the interlocutors had gone through and the discrepant ideologies, values, norms and expectations they held. Ting-Toomey (1998), in this regard, proposed that "many intercultural miscommunication episodes start off from well-meaning clashes", by which she meant the misunderstanding encounters, in which people try to behave properly and effectively, nevertheless, quite ethnocentrically, according to their own cultural norms, which might be considered improper in another culture. Accordingly, successful intercultural communication was considered to be heavily indebted to a conscious awareness of how different cultural value dimensions affect the symbolic exchange process between participants in an interactive situation.

Therefore, ICC studies scrutinized and compared the communication practices of different cultural groups, to identify and expand shared content meanings among them (Ting-Toomey, 1998; Gudykunst, 2003). This tradition of ICC studies drove language instruction toward the objective of promoting the students' knowledge of the different communication norms and rules, various identity groups applied in different situations, to increase their competence for intercultural communication. Thereupon, critical eyes of textbook evaluation studies were directed toward the representation of identities in language textbooks and their comprehensiveness in fulfilling the students' intercultural communication needs. Shardakova and Pavlenko (2004), for instance, examined two Russian textbooks, designed for American students to determine the extent to which identity representations in the books were embracive of the diversities among the actual audianceof the book. Biases and oversimplifications in the texts were taken as lost opportunities for cross-cultural reflection and a potential for the students' resistance of the target culture and a barrier to their further investment in the target language. Hence, the authors recommended that foreign language textbook writers incorporate difficult unequal encounters language learners are likely to negotiate in the target language context. A host of other studies, analyzing identity representations in language textbooks, suggested that authors depict identities relevant to the learners' social and political lives and avoid stereotyping and biased representations (Canagarajah, 1993; Kinginger, 2004; Siegal \& Okamoto, 1996; Talburt \& Stewart, 1999).

Further enlightening for materials developers in this tradition of intercultural studies was Ting-Toomey's (1998) conception of mindful intercultural communication. The key to effective intercultural communication, she believed, was mindful intercultural communication, which requires a conscious monitoring of one's reactive emotions in judging negatively communication differences that arise from cultural differences. In other words, successful intercultural communication entails a development of the ability to view the world from others' perspective. To this, Deardorff (2006) also pointed, indicating that interculturality entails a state in knowledge, attitude and skills that gives one an understanding of and respect for diversity, with the added flexibility and adaptability in behavior to treat others as they expect to be treated. Byram (2000) also agreed with this conception of intercultural competence, contending that it entails the following components:

1. Attitudes (Savoir être): Relativising self and valuing other

2. Knowledge (Savoirs): Knowing oneself and the other; knowing the individual and societal aspects of interaction 
3. Education: Having critical cultural awareness and political education

4. Skills of interpreting and relating (Savoir comprendre): Having the ability to interpret a document or event from another culture, to explain it and relate it to documents from one's own culture

5. Skills of discovery and interaction (Savoir apprendre/faire): Manifesting the ability to evaluate critically and on the basis of explicit criteria, perspectives and products in one's own and other cultures and countries.

These elements were also embraced in the model Byram and Esarte-Sarries (1991) and Feng and Byram (2002, p. 63) proposed as the fundamentals of intercultural authenticity, or "the presence of 'realist' representations of cultures, including the target culture and the learners' own", in language textbooks. The first salient characteristic of an interculturally authentic material they considered in its mutual perception of the interlocutors, or selection, not only of the materials produced by native speakers, but also the ones created by those using the language as a lingua franca, including the people of the learners' own culture. To this they added the significance of considering the 'real' intention of the spoken or written discourse through the available linguistic or pragmatic cues, by textbook writers. Balancing of diachrony and synchrony in incorporating texts reflecting the historical development of the language and culture and its contemporary state, was the other criterion they found significant in making a text interculturally authentic.

Nevertheless, as the development of modern technology and mass media further removed the boundaries delimiting cultural units and facilitated direct relationships among individuals, studies of intercultural communication detracted their attention from the conception of culture as "imagined communities" (Anderson, 1991) to a view of it as a discourse construction (Scollon \& Scollon, 2001; Piller, 2007; Heartog, 2006). In this approach, the assumption is that cultures are such "large, superordinate categories" (Scollon \& Scollon, 2001, p. 138) that do not apply to all individual members of each cultural community. Therefore, taking culture and cultural community as the basis for the analysis of intercultural communication is considered to be misleading in this approach, since as Scollon and Scollon (2001) indicate, communications occur between and among the people who talk to each other, and not between cultures. In this sense, all communications are interpersonal and no interaction is intercultural, as it was presumed in the previous tradition. If cultures come into contact with another, it is through the discourse of the people; therefore, discourse, it is believed, must be the unit of analysis in the studies of intercultural communication (Scollon \& Scollon, 2001; Hartog, 2006). Thereupon, studies in this tradition "set aside any a priori notions of group membership and identity and ... ask instead how and under what circumstances concepts such as culture are produced by participants as relevant categories for interpersonal ideological negotiation" (Scollon \& Scollon, 2001, p. 544). Guided by this conception of culture and communication, researchers have devoted their attention to exploring differences in linguistic structures (e.g. Wierzbicka, 2003), discourse structures (Scollon \& Scollon, 1995 and 2001), Speech acts (e.g. Blum-kulka, House \& Kasper, 1989), pragmatics (Wierzbicka, 2003), expression of emotions (Wierzbicka, 1999), cognition (Gudykunst, 1995) and social systems (e.g. Hofstede, 1980) between peoples of different cultural backgrounds.

This tradition of intercultural discourse was a guide for many researchers to evaluate the representation of pragmatics in language textbooks. The results revealed that many textbooks tend to offer classroom learners little opportunity for learning L2 pragmatics (e.g. Pearson, 1986; Myers-Scotton \& Bernstein, 1988; Bardovi-Harlig, 2001; Wong, 2002; Vellenga, 2004), as either not presenting speech acts or presenting them unrealistically. Boxer and Pickering (1996), for instance, found indirect complains, i.e. complaints about oneself or someone absent in the conversation, almost nonoccurring in language textbook, perhaps as an attempt on part of materials developers not to distort the utopian world of language textbooks. A case for the unrealistic representation of speech acts was the formulaic 'Thank you' as a complement response, which appeared as the only choice in Korean ELT materials Han (1992) investigated, making it the only option for the students to resort to. Boxer and Pickering (1985) attributed the reason for such misleading representation of speech acts in language textbooks to their reliance on native speakers' intuition in the linguistic expression of the speech acts, which nonetheless is found generally unreliable (Wolfson, 1989; Boxer \& Pickering, 1985). The inefficiency of language textbooks in promoting the students' pragmatic and linguistic repertoire has been further attributed to the little information they provide concerning the role relationships between participants in the interactions or the meta-pragmatic information about when and where it is appropriate to perform a particular speech act (Brown \& Levinson, 1978, 1987; Nguyen, 2012).

With a view of interculturality as the main objective of language instruction and acquisition in today's age of globalization, the current research was conducted to investigate the extent to which socialization in the world of Top Notch and Summit textbooks can prepare the learners for the challenges of global communication in this era. The analysis concerns both the identity the books intend for the learners to promote and the repertoire of discursive items they offer, as a clue to the level of competence they aspire for the learners to attain.

\section{Research Questions}

The research study seeks to provide answers to the following questions:

1. To what extent can identity representations in Top Notch series promote interculturality in the learners?

2. To what extent is interculturality a concern in the representation of identities in Summit series?

3. Can the repertoire of discourse options in Top Notch series develop the competence for intercultural communication in the learners?

4. Are the discourses in Summit series intercultural? 


\section{Research Method}

\subsection{Materials}

The assessment of interculturality was conducted in the current investigation on textbooks selected from Top notch and Summit series, designed by John Saslow and Allen Ascher (2006) for the adults and young adults. Top Notch is a sixlevel English course, aiming to take the learners to the top notch of competence in intercultural communication with both native and nonnative speakers of English. Every textbook consists of five units, each starting with a topic preview section, followed by Sound Bites that presents a piece of natural conversation. The unit continues with two more conversations, introducing new grammatical issues and/or vocabulary and idiomatic expressions and listening and pronunciation activities. Summit, on the other hand, is a four level course, designed to follow Top Notch or any other intermediate courses. Similar sections as in Top Notch constitute the body of every unit in Summit, with the difference being that listening, writing and idiomatic expressions gain more significance here. For the purpose of the study, three textbooks were selected from Top Notch, one from each of the beginning, intermediate and upper intermediate levels, and two from Summit series, for the investigation to fully embrace the world learners are exposed to in the books.

\subsection{Data Analysis}

The purpose of the current investigation was to assess the potential in Top Notch and Summit series to prepare EFL learners for intercultural communication. The analysis was conducted at two levels. Primarily, based on Ting-Toomey's (1989) conception of identity negotiation theory, the repertoire of identity options in the books was inspected. At this level, the focus of the analysis was on the reading passages and pictures in the books. Moreover, following Scollon and Scollon's (2001) model of discourse structures, the study went further in its analyses to scrutinize the conversations in the books to determine the extent to which they were representative of the interaction among members of diverse cultural groups.

\subsection{Analysis of Identity Options}

Following Ting-Toomey's (1981) identity negotiation theory, the study defined identity as the reflective self-conception each person derives from their peculiar cultural, ethnic and gender socialization processes. In analyzing identity options in the books, the study aimed to determine the extent to which the books were adequately representative of the knowledge required for various identity groups to successfully communicate with one another. Ting-Toomey (1998) defines eight identity domains, which she assumes can play a critical role in the mindful intercultural communication process. They are discussed as cultural identity, ethnic identity, gender identity, personal identity, role identity, relational identity, facework identity and symbolic identity. The first four identity domains (cultural identity, ethnic identity, gender identity and personal identity) she refers to as primary identities, as exerting a crucial, continuous effect on individuals' behavior all through their lives. The other four identity domains (role, relational, facework and symbolic identities) she regarded as situational, changing from one context to the next. Primary identities constituted the main focus of the current investigation, given its limited scope. The identities were defined as follows:

\subsubsection{Cultural Identity}

Following Ting-Toomey (1998), the study investigated cultural identity in terms of the individualistic and collectivist values depicted in the texts. Individualistic values were detected through the themes of consumerism, thrift (Hamilton, 2010; Hofstede \& De Mooji, 2010; Huang, Huang \& Syu, 2010), gratification of competition (Hofstede \& De Mijoo, 2010), self-direction (Imada, 2012) and social isolationism (Huang, Huang \& Syu, 2010), generally associated with individualism. Collectivism, on the other hand, was investigated via the themes of conformity and group harmony (Hofstede, 2001; Hofstede \& De Mooji, 2010; Imada, 2012) throughout the reading passages in the books. In thus analyzing the cultural values, the aim was, on the one hand, to determine the extent to which the books, in representing the values of the two cultural orientations tried to raise the learners' cognizance of them as a prerequisite for success in mindful intercultural communication (Ting-Toomey, 1998). Moreover, the representation of identities in the books could demonstrate their own reception of diversity in their audience's cultural values.

\subsubsection{Ethnic Identity}

Ethnicity is, as Ting-Toomey (1998) indicates, another aspect of identity, which can play a significant role in intercultural communications. In defining ethnic identity, Ting-Toomey (1998) made a distinction between the value and salience of ethnicity, with the former referring to one's ancestral inheritance, including their shared race, nationality, language and religion with an ethnic community and the latter to one's sense of allegiance with the group and their attempt to maintain their intergroup bounds. The significance of ethnicity in intercultural communication is best realized when the participants are either unaware of the discrepancies in their national values, or consciously behave according to their distinctive national values, to mark their particular group membership. The study, therefore, investigated the extent to which ethnic identity, as a significant force on intercultural communication has been a matter of concern in Top Notch and Summit series. Primarily, the content of ethnic identity was detected in the books through the criteria of nationality, race and language background of the characters appearing in the texts, specifically in the Sound Bites sections and the conversations. Further of concern in the analysis was the depiction of different national values as a means to promote the learners' understanding and tolerance of diversity, a prerequisite to becoming interculturally competent. 


\subsubsection{Gender Identity}

In inspecting gender as an aspect of human identity in the interactions in the books, the study followed the objective of verifying the extent to which they could prepare the learners to interact successfully with an opposite gender. Given the stereotypical conceptions about females and males that existed, or do exist still in some cultures, some regard the gender of their interlocutor as a barrier in communication. Therefore, removing this obstacle was regarded as a significant obligation for the books as regarding intercultural communicative competence in language acquisition. Accordingly, the study focused in its analyses, primarily on the way the books dealt with gender stereotypes in their representation of gender identity. Such gender stereotypes included the depiction of women, for instance, in the role of an affectionate nurturing housekeeper and men as a competitive, emotionally reserved breadwinner (Ting-Toomey, 1998). The study further focused on the conversations in the books, on the one hand to investigate the frequency of the encounters between the two genders, their efficiency and the extent to which the stereotypes, concerning the superiority of one over the other, governed their relationships.

\subsubsection{Personal Identity}

An individual's sentiments and information about their own personal self-image constitutes their personal identity (Ting-Toomey, 1998). Accordingly, personal identity can be defined at two levels, actual personal identity and desired personal identity. Actual personal identity refers to the unique attributes an individual constantly exhibits in their behavior and with which they are constantly identified by others. Desired personal identity, on the other hand, Cahn (1987) defines as the preferred attributes an individual regards to be assets in an interaction. Supporting others' desired identities more than their actual identities, according to Ting-Toomey (1998), is significant for successful intercultural communication. This issue will be more fully dealt with in study of the discourses in the books, when considering the facet of face saving.

\subsection{Analysis of Discourse Structures}

The study further investigated interculturality in the books through the discourses they presented. The assumption was that not only is the development of a multicultural identity significant for intercultural communication, but so is the promotion of the requisite discourse competence to deal with the challenges of intercultural communication. To this end, based on Scollon and Scollon's (2001) model of discourse system structures, the study analyzed the conversations in the books to determine the extent to which they could provide the learners the opportunity to practice communication in various discourse systems. The analysis could further give way to an identification of the ideological and cultural values the books tended to perpetuate.

In this approach, the researchers analyzed the conversations in the books according to the face saving and politeness strategies used by the participants. Scollon and Scollon (2001) propose three politeness systems, which develop with variations in power and distance, namely the deference, solidarity and hierarchy.

The deference politeness system is one in which participants are assumed to be equal or near equals, but treat each other at a distance, as the relationships among professional colleagues who do not know each other well. Characteristics of this system are, on the one hand that it is symmetrical (-P), that is, participants regard themselves as equal in social status, and on the other hand, that it is distant $(+D)$, with participants using independent strategies talking to one another, for instance, calling each other with a surname and title. This strategy is, according to Scollon ns Scollon (2001), characteristic of the egalitarian ideology, associated with the cultural value of individualism, but participants try to maintain deferential distance from one another.

The Solidarity politeness system is another face saving strategy, most typical of the egalitarian ideology, observed in the relationships between close friends and colleagues. Characteristics of such interactions are that they are symmetrical (P), with no power distance among the participants and close (-D), meaning that the interlocutors use politeness strategies of involvement, feeling or expressing closeness, warmth and friendship to each other, referring to one another in first name, for instance.

In the hierarchical politeness system, however, the participants recognize and respect the differences that place one in a superordinate and the other in a subordinate position. The main characteristic of this system is the recognized difference in social status and power $(+\mathrm{P})$ among the participants, making the relationship between them asymmetrical. The participants, therefore, do not use the same face politeness strategies talking to each other. The person in superordinate or upper position uses involvement strategies in speaking 'down' with the one in subordinate or lower position using independent strategies speaking "up". This sort of hierarchical face system is quite familiar in business, governmental and educational organizations.

According to Scollon and Scollon (2001), miscommunications often occur when participants have a different assessment of each others' status in relation to one another, thus, each using a politeness strategy, which to the other sounds bizarre and inappropriate. This is particularly the case when one is new to a group, language or culture, and is thus unaware of how to express the rather subtle differences in face values. Therefore, analyzing the conversations in the books, the study tried to assess the books according to the range of opportunities they provided for the learners to acquire how to express face values in the target language, according to various contextual demands.

\section{Results and Discussion}

To answer the four questions proposed as the basis of this study, illustrations and reading passages and conversations were analyzed in five language textbooks selected from Top Notch and Summit series, for the diversity of sociocultural identities they addressed and the scope of discourse systems they covered. The aim was ultimately to discuss the 
likelihood with which the books could enhance intercultural communicative competence in the learners. The results were found to be as follows.

\subsection{Repertoire of Identities in Top Notch and Summit Series}

\subsubsection{Cultural Identity}

Cultural identities were investigated in the selected textbooks in terms of the themes of individualism and collectivism. The results suggested similar consideration and respect for different value orientations, although individualism was more glorified. In fact, the theme of individualism versus collectivism was pervasively noticeable in the books analyzed. Where nuclear families were introduced, extended ones were also referred to. Individualists' preferences for singularity, freedom of choice based on personal values were set against the collectivists" "sexism", "double standard" and "old-fashioned" culture. Democracy came in contrast to dictatorship. However, as an inevitable result of manifesting this binary opposition in the books, individualism apparently gained superiority over collectivism, in the references made, for instance to "an individualist" wishing to be who he is, regardless of what others say about him (Top Notch 2); or the previously collectivist cultures like Japan, deciding to give up their "cumbersome" and "oldfashioned" cultures for an "opener" and a more "competitive" one (Top Notch 3A, p. 10). This was, nevertheless, made up for in the questions raised in the Interaction and Discussion sections, which not only allowed the learners to express their individual sides freely, but also encouraged them to give their judgments a second thought, or to think of the occasions in which either of the two poles of the binary opposition could be true.

Top Notch, as the discussion suggests so far, defines its circle of audience so vast and inclusive as to comprehend diverse, and at times even discrepant social and cultural identities and values. Although the middle/upper middle class was the only social group invoked in Top Notch, the cultural values of individualism, typically associated with this group, were not the only ones addressed in the books. This approach could be interpreted in terms of the modernist assumptions of disbelief in the social and cultural stereotypes and conventions that underlie the series. Putatively, compatible with its intercultural purposes, Top Notch tries to have an etic and universal view of human values, seeking to bring generalization across cultures (Watkins, 2011).

However, the analysis of the content in Summit series suggested that the approach to the depiction of diversity, pervasive in Top Notch ceased in the representation of cultural identities in the Summits. Indicative of individualism in the studied textbooks were the references made to the falling birthrates and the general tendency in families to become nucleus (Summit 1B, 2B) or the children who have become disobedient (Summit 1B). The depiction of a media saturated society, where the attraction to technological advancements has deprived people of their free time and leisure activities (Summit 1B), thus creating workaholic individuals who burn the candle at both ends (Summit 1A, 2B) is further suggestive of a highly individualist society (Huang, Huang \& Syu, 2010). Moreover, the pervasive themes of consumerism and thrift, portrayed under the topic of advertisement and consumption or through such notions as the habit of compulsive shopping (Summit 1B) and different tips to develop high financial IQ, as well as the illustrations depicting the consumer market of America, are closely tied to the cultural values of individualism (Hamilton, 2010; Huang, Huang \& Syu, 2010). Moreover, the policy of "Green Consumerism" adopted by governments in consumer based societies to bring about a more sustainable relationship between humanity and nature, was discussed in the books under such topics as "Green Dealership" (Summit 2B), "Animals" and "Protecting Our Natural Inheritance", pointing to another characteristic of individualist western societies with which learners get familiar in Summit series (Hamilton, 2010).

Given the highly cultural content of the textbooks in Summit series, purveying unilaterally the culture of western societies, one may possibly argue that the books are trying to persuade their audience to assimilate the target culture, if they deem to become a member of their community. The argument might sound quite convincing, taking into account the homogeneity of the sociocultural identities depicted in the books, which may well be interpreted as an attempt to naturalize the values of individualism as the only ones dominant worldwide. This will stand against the attitude of respect and acceptance of diversity required for intercultural communication in the age of globalization (Byram, 1997; Deardorff, 2006). If the world is going toward pluralism and heterogeneity, what learners need is not so much to know about the values of a particular culture to become a European or American, but to learn to celebrate and cope with diversity and difference.

However, from a different perspective, this domination of the cultural forms of individualism and modernism (valorization of science and technology) may be justified, according to Baraldi (2006), as two of the basic cultural forms exported through globalization, hence the reality of the world. Even so, still missing in Summit is the culture of pluralism, the unity of differences and communicative confrontation between different cultural forms arising in differently structured societies, which according to Baraldi is another value, indispensable to the evolution and existence of a multicultural society, the ultimate result of globalization. Therefore, more than a pure representation of the cultural values of individualism, Summit, it may be contended, would do better introduce and bring into contact different social and cultural identities to foster "hybridization" (Pieterse, as cited in Baraldi, 2006, p. 60) and produce "métissage", a fusion of different cultures, each with its own history and tradition (Wieviorka, as cited in Baraldi, 2006, p. 60).

\subsubsection{Ethnic Identity}

The investigation of ethnic identity was based on the criteria of nationality and national customs and traditions, race and language background. Concerning the subcategory of natural phenomena and living surrounding, many of the conversations took place in nonnative contexts such as Japan, China or Malaysia. Moreover, in the introduction of 
natural phenomena, examples were provided of the ones occurring in different parts of the world (e.g. earthquakes in Japan, China, and Bam in Iran; influenza epidemic in Indonesia). Parallel to the introduction of western products, eastern books, inventions (e.g. Japanese invention of the printing press) and achievements were also presented, although in fewer numbers. When holidays and traditions were introduced, the Korean Chuseok and Harvest Moon Festival, Muslims' Eid ul-Fitr and Indians' traditional wedding ceremonies were not disregarded. Where nationality was concerned, Europeans, Americans and non-European Americans, such as Japanese or Chinese all appeared in the books, almost equally.

On the contrary, Summit series, as the analysis suggested, have apparently been constructed to portray life in a European and American society. Almost all the conversations and events in the books occurred in such a context, in countries or cities such a Los Angles, New York City, Brazil, London and Paris. In very rare cases did any Eastern city appear in the texts. Natural phenomena such as Bermuda Triangle, The Loch Ness Monster, explosion in Tunguska, Siberia, Stonehedge (England), the Nazca Lines (Peru) and Atlantis (Greece) did not allow for the occurrence of any Eastern ones in Summit. The same was true of such western products as wigs and extravagant clothing, electric massage chair, Riviera Pool Chair, Porta Bells or brand name perfumes. Needless to refer to events such as War in Western Europe, 30 year's war in central Europe, October Revolution (Russia), Canary Island (Atlantic Ocean) and Bigfoot in the U.S. that totally occupied the scene in Summit series.

Presumably, having introduced the world culture and brought learners to the top notch of intercultural competence, Summit series now find it time to prepare them for life in a globalized context as that of a western society, hence the introduction of various aspects of their culture. This is the information, it is assumed, that they require to be communicatively competent in the target language and to reach the summit of language proficiency, to use the language as a native speaker. As a result, almost no trace can any longer be seen of the lingua franca English or any non-western identities.

\subsubsection{Gender Identity}

Heterogeneity was further noticeable in Top Notch in terms of gender representation. A great attempt seemed to have been made in the books to avoid gender discrimination, as females and males appeared almost equally in the texts, with females making $55 \%$ and males about $45 \%$ of the total characters in the books scrutinized. However, this equality did not appear to have been maintained in the roles ascribed to them. Females still appeared more recurrently as nurturers and victims and less often as workers. In fact, $65 \%$ of the occupational roles in the books, analyzed, were occupied by men. Nevertheless, concerning the type of interactions in the books, they occurred between members of the same gender and the opposite gender almost equally and no indication of superiority or inferiority was observed between them; just as females would ask males for help, for instance, to solve their computer problems (Top Notch 2B), so did males of females. In fact, in the interactions in Top Notch, gender was not the defining feature of the characters; females and males interacted with the opposite gender just as they did with members of their own gender. This approach is approved of in Ting-Toomey's (1998) identity negotiation theory, according to which for successful intercultural communication, those attributes must be supported, which the participants find an asset. Masculinity and femininity are features that are socially constructed and thus differ from one society and individual to the next. Accordingly, the books, as it appeared avoided setting such stereotypical attributes as a base in the interactions they presented to foster intercultural communication.

Nevertheless, from a rather different perspective, one could still take this lack of presentation cases where gender identity gets highlighted in the interactions between individuals, as a deficit for the books, not presenting the world as it really is, with power inequalities between individuals, hence not preparing them for the real world challenges of intercultural communication. Nevertheless, this is, according to Piller (2007) and Shi-xu (2006), the most significant aspect of intercultural communication and the main source of all miscommunications, which apparently have been circumvented in the books.

In spite of its different approach in depicting cultural and ethnic identities, Summit, as it appeared, followed the same strategies, as in Top Notch representing gender identities. Females and males appeared with almost the same frequency throughout the books in their un-stereotyped roles, in their un-stereotyped roles. Similar to Top Notch, the participants felt free in their interactions with members of their opposite gender, and the traditional expectations and standards of masculinity and femininity, defining power for the individuals were not a matter of concern here. At this point, the inadequacy of gender identity representations in Top Notch can be better identified. Summit, as it was stated before, is a typical representation of an individualistic western society and apparently aims to prepare the learners to adopt the cultural values of the target society. Top Notch on the other hand, is the locus of diverse cultural values, both individualistic and collectivist, and it aims at promoting the learners' competence for intercultural communication with both native and nonnative speakers of English. Therefore, representing restrictively inter-gender interactions governed by the ideology of individualism could restrain the learners' repertoire of interculturality.

\subsubsection{Personal Identity}

So far as the conversations and Sound Bites sections were concerned, very few instances were observed of the characters referring to an aspect of each others' personal identity features (e.g. Top Notch 2B); where there were such references, they appeared merely in the listening sections. This could be taken as another instance of an Achilles heel for the books, not instructing the learners, for instance, how to support their own and others' personal identities in the target language. Nevertheless, as Ting-Toomey (1998) indicates, real world intercultural communication is full of 
threats to identity threats, for which the learners might not get prepared undergoing socialization merely through the peaceful world of Top Notch.

Therefore, in short, the investigation of identity representations in Top Notch series suggests that to promote learners' competence for intercultural communication, the books did well in their attempt to enhance learners' understanding of diversity in cultural values, juxtaposing individualism and collectivism and raising reflective questions for the learners to decide on their own side. Exposing members of diverse national identities in communication with one another and introducing the introducing the national traditions of various countries could be regarded as another virtue in the books, promoting the acceptance of diversity in national and ethnic identity among the learners. Where gender identity was concerned, the books avoided representing individuals in terms of the stereotypical conceptions of femininity and masculinity, both in the conversations and other parts of the books. Nevertheless, contrasting the world of Top Notch with the with the world in reality, one could observe deficits in the books in not demonstrating the power discriminations in the world, found in effect as the main source of miscommunication in intercultural interactions. While this approach to identity representation could be interpreted as an attempt to remain objective and avoid reinforcing such discriminations, misrepresentation of them could restrict the learners' repertoire of discursive elements to deal with the challenges of the real world intercultural communication.

In the representation of personal identity, Summit again followed about the same approach as in Top Notch, refraining from depicting individuals directly referring to any aspect of each others' personal identities. Nevertheless, this is not to disregard the rich source of vocabulary items and idiomatic expressions the books provide for the learners to learn how to define their personalities in the target language. However, what was missing in the texts, as in Top Notch, was the way the pragmatic repertoire they need to have to be able to support their identities when exposed to threats. The significance of this insufficiency in the books can be better realized, as considering the results of the analyses of discourses in the two series.

\subsection{Discourse Structures in Top Notch and Summit Series}

From among the three discourse styles and politeness strategies Scollon and Scollon (2001) specified, solidarity and to a lesser extent deference appeared the only ones observed in the conversations in Top Notch. The dialogues either occurred between those equal in social rank and status, for example between friends and colleagues, or in thefew cases, where they appeared between those belonging to diverse social groups, their differences were not their highlighted features in the interactions, evidently as they perceived each other to belong, at least to the same discourse group. Accordingly, the involvement politeness strategy was predominantly observed in the conversations; the participants felt free to express their own positions directly and clearly and preferred the informal discourse style to converse with one another. This style of discourse, according to Scollon and Scollon (2001), is characteristic of the Utilitarian discourse system, which has the preference for appeal, commonness and free individual expression as its keystone. Within this culture, there is a "reinforced emphasis on direct talk, on avoiding elaboration and extravagance and on promoting close egalitarian social relationships" (p. 127), the vey features indicated as governing the conversations in Top Notch. Utilitarianism, furthermore, "has little tolerance for hierarchical social relationships" (p. 127), hence the absence of any discourses between individuals of asymmetrical power relationships.

Nevertheless, although utilitarianism is getting more widespread as an international discourse style, one could question Top Notch for its absolutist and universalistic approach to the selection and presentation of discourses, making it insufficient as a source to enrich the learners' competence for intercultural communication. Absolutism is evident in the discourses of Top Notch as they depict the utilitarian style so predominantly as if it were the single mode of discourse, learners needed to acquire. This misconception could hamper the learners' competence, primarily as not acquainting them with other discourse ideologies, face systems and politeness strategies, replete in day-to-day communications. "Communications in home, communications between men and women, communications of members of different generations and communications among members of different ethnic groups all show major departures from the patterns of this [Utilitarian] discourse system" (Scollon \& Scollon, 2001, p. 130). Utilitarianism, even if the most common of all business, government or academic styles, does not occupy the entire field of discourse, even within a single culture. Context determines the particular style of discourse that need be adopted. Nevertheless, restricting learners merely to this system, as did Top Notch, could give them a competence, too narrow to deal successfully with the challenges of the real world communication.

Further deficient in Top Notch could be its misconceived treatment of utilitarianism as the one natural and rightful state of human life and the single cultural ideology determining the individuals' communication behavior. Accordingly, as indicated previously, all characters in Top Notch, regardless of their diverse sociocultural identities, were depicted as members of the same discourse community, hence the commonalities on which they based their symmetrical interactions. Evidently, as the results of the study to this extent suggested, Top Notch is based on a conception of intercultural communication, which is far distant from what Scollon and Scollon (2001) prefer to call interpersonal or inter-discourse communication. Intercultural communication appears to be purely the contact of diverse cultures and ethnicities with one another, rather than the people holding such identities and their discourses, probably either because it regarded socialization and discourse as two distinct and isolated factors, or as it assumed everyone to have given up their own style of discourse in turn for the globalizing utilitarian style. The first assumption sounds farfetched, as no one can deny the effect of socialization and culture on the kind of language and communication style individuals develop (Deardorff, 2006). The same is true of the second assumption as well, where the fact is considered that, as indicated before, not even the members of the utilitarian discourse community use the style all the time in all contexts (Scollon $\&$ Scollon, 2001). Therefore, such representation, merely of the utilitarian discourse style, could distance the world of Top 
Notch from the reality, thus not adequately preparing them for the complexities they might face in the real world intercultural communication. Of such complexities, one can indicate the power differences and miscommunications that arise when the two participants communicate through different discourse systems and have different assessments of the face strategies used (Scollon \& Scollon, 2001). Nevertheless, given the ubiquity of communication style Top Notch assumes for all its characters and its audience alike, it seems short of the potential to thus empower the learners. As for intercultural, or inter-discourse, communicative competence, Scollon and Scollon (2001) point out two main prerequisites:

Professional communication depends on learning to move with both pragmatic effectiveness and cultural sensitivity across such lines, which divide discourse systems. ... Pragmatic effectiveness in communication means participating as fully as possible in the discourse systems of those with whom one is wishing to communicate, while never taking their requirements as simply self-evident. Cultural sensitivity means being conscious of the ways in which one's own communication may be perceived and also accepting the fact that one is never considered to be a full member of the discourse systems in which one will participate (p. 134).

Evaluating Top Notch on this basis, with the criterion of pragmatic effectiveness, one could criticize Top Notch, on the one hand, for not fully presenting the discourse practices of the target community in all contexts and for depicting merely their use of the utilitarian style. On the other hand, there is its depiction of utilitarianism as the "self-proclaimed "standard" of international discourse", which as Scollon and Scollon (2001) indicate, "can be shown not to be all that it claims to be" (p. 133). Nevertheless, Top Notch, with its reception of diversity and portrayal of varied cultural value systems, sounds to be an effective source of elevating the learners' cultural sensitivity for the purpose of intercultural communication. In other words, considering the prerequisites of interculturality Deardorff (2006) pointed out, i.e. attitudes, knowledge and skills, Top Notch appears to have set its objective on promoting the requisite knowledge and attitude in the learners, but not the skills learners need to develop.

The analysis of conversations in Summit gave about similar results, as it was found in Top Notch, for the structure of discourses in this set of textbooks. The utilitarian discourse system was ubiquitously observed throughout the books, even more strongly here, since it was not only the pervasion of solidarity and involvement politeness and face strategies that reflected utilitarianism, but also the context and culture of western societies, the recurrent themes of egalitarianism and individualism throughout the texts. These are, indeed, the very characteristics, with which Scollon and Scollon (2001) identify utilitarianism. Similar criticism, therefore, can be raised against the system of discourses in Summit, as it was for Top Notch, in spite of the different objectives identified for each. Although Summit, as indicated previously, seems to follow the objective of assimilation with its sociocultural identity representation, its exclusive representation of the utilitarian discourse structures could still restrict the repertoire of discursive elements learners can develop, since this is not the only discourse system that the members of the target culture use in all contexts (Scollon \& Scollon, 2001). Therefore, Summit, as well, seems to be subject to the critique of insufficiency as a source to enhance the learners' pragmatic effectiveness for professional communication, even exclusively with the members of the target discourse community.

\section{Conclusion}

The study investigated the representation of sociocultural identities and discourse structures in Top Notch and Summit series, to assess them as a collection of textbooks intended for the nonnative learners of English at different levels, aiming to acquire the language for intercultural communication. Different results were found for the two series. Top Notch, addressing the beginners and intermediate level students proved rich as a source to enhance the learners' cultural sensitivity, given its reception of diversity in sociocultural identities among the learners and depiction of the value systems of diverse national and cultural groups. Nevertheless, such reception of heterogeneity seemed to cease when the system of discourses in the books was concerned. Utilitarianism, the solidarity and deference politeness strategies and the involvement face system, associate with that, constituted the communication system ubiquitously observed throughout the books. This was found as a fallacy in the books, not capable of making the learners pragmatically effective for intercultural communication. Summit, on the other hand, addressing upper-intermediate and advanced learners, seemed to be following a different objective. Apparently, assuming its audience to be competent enough for intercultural communication, the books followed the goal of acquainting the learners more with the culture of individualism, characteristic of western societies, probably to socialize them as a member of such communities, whose values are becoming globalized. The books, therefore, became homogeneously the locus of individualistic cultural values, both in terms of the depicted sociocultural identities and discourse structure system. Accordingly, they maintained the approach of Top Notch in presenting exclusively the utilitarian discourse style, but replaced its diversity of sociocultural identities with a homogeneous portrayal of individualistic identity values.

Juxtaposing the results of the two analyses, one can see that the kind of socialization Top Notch and Summit English courses provide altogether can be sufficient in raising the learners' cultural sensitivity and enhancing their apprehension of diversity; however, it cannot adequately promote their pragmatic competence for intercultural communication. Intercultural communication does not merely require the attitude and knowledge for the reception of diversity, but the skills as well to understand such diversity when they manifest in the communication practices of the people. Therefore, Top Notch, for instance, could do better, had it demonstrated how the diverse sociocultural identity values it depicted could affect the communication practices of the groups their consequent effect on intercultural communication. Moreover, the absence of any hierarchical interactions between participants of unequal social status in both the two books could further restrict the learners' resources for communication such conditions. Therefore, it seems 
recommendable for materials developers to consider utilitarianism as an ideal but by no means the only system of communication learners need to acquire for intercultural communication.

Nevertheless, it was found beyond the scope of the current study to scrutinize and assess the range of speech acts presented in the books as a clue to the breadth of their pragmatic repertoire. Moreover, the present study was purely a text analysis, not taking into how the books actually affect the learners' competence for intercultural communication, especially when the teaching methodology and policies of different institutions are concerned. Therefore, future studies are required to thus complement the results of the current investigation.

\section{References}

Anderson, B. (1991). Imagined communities: Reflections on the origins and spread of nationalism. London: Verso.

Alptekin, C. (1993). Target language culture in EFL materials. ELT Journal, 47,2, 136-143.

Baraldi, C. (2006). New forms of intercultural communication in a globalized world. The Intercultural Communication Gazette, 68, 1, 53-69.

Bardovi-Harlig, K. (2001). Evaluating the empirical evidence: Grounds for instruction in pragmatics? In: K. Rose, \& G. Kasper, (Eds.), Pragmatics in Language Teaching. Cambridge: Cambridge University Press, 13-32.

Boxer, D., \& Pickering, L. (1995). Problems in the presentation of speech acts in ELT materials: The case of complaints. ELT Journal 49, 1, 44-58.

Brown, P., \& Levinson, S. (1978). Universals in language usage: Politeness phenomena. In: Goody, E. (Ed.). Questions and Politeness: Strategies in social interaction. Cambridge: Cambridge University Press, 56-289.

Brown, P., \& Levinson, S. (1987). Politeness: Some Universals in Language Usage. Cambridge: Cambridge University Press.

Byram, M. (1997). Teaching and assessing intercultural communicative competence. Clevedon: Multilingual Matters.

Byram, M. (2000). Assessing intercultural competence in language teaching. Sprogforum, 18, 6, 8-13.

Byram, M. \& Esarte-Sarries, V. (1991). Investigating cultural studies in foreign language teaching. Clevedon: Multilingual Matters.

Canagarajuh, S. (1993). American textbooks and Tamil students: Discerning ideological tensions in the ESL classrooms. Language, Culture and Curriculum, 6,143-156.

Cook, V.J. (ed.) (2002). Portraits of the L2 User. Clevedon: Multilingual Matters.

Deardorff, D. K. (2006). The identification and assessment of intercultural competence as a student outcome of internationalization at institutions of higher education in the United States. Journal of Studies in International Education, 10, 241-266.

Deardorff, D. K. (2009). The Sage Handbook of Intercultural Competence. Sage Publications: United Kingdom.

De Mooij, M. \& Hofstede, G. (2010). The Hofstede model Applications to global branding and advertising strategy and research. International Journal of Advertising, 29 (1), 85-110.

Feng, A., \& Byram, M. (2002). Authenticity in college English textbooks - an intercultural perspective. RELC Journal, $33,2,58-84$.

Gudykunst, W. B. (1998). Language and ethnic identity. Clevdon: Multilingual Matters

Gudykunst, W. B. (2003). Cross-cultural and intercultural communication. California: Sage Publications.

Hamilton, C. (2010). Consumerism, self-creation and prospects for a new ecological consciousness. Journal of Clear Production, 18, 571-575.

Han, C. (1992). A comparative study of compliment responses: Korean females in Korean interactions and in English interactions. Working Papers in Educational Linguistics, 2, Fall, 17-31.

Heartog, J. (2006). Beyond 'misunderstandings' and 'cultural stereotypes': Analysing intercultural communication. In B. Bührig \& D. J. ten Thij (Eds.), Beyond misunderstanding (pp. 175-188). Switzerland: John Benjamins Publishing Company.

Hofstede, G. (2001) Culture's consequences (2nd ed.). Thousand Oaks, CA: Sage.

Huang, J. J., Huang, M. Y. \& Syu, F. K. (2010). Liberated Anomie in Generation Next: Hyperindividualism, extreme consumerism, and social isolationism. Fujin J Health Sci, 2, 2, 41-47.

Hultgren, A. K. (2011). 'Building rapport' with consumers across the world: The global diffusion of a call center speech style. Journal of Sociolinguistics, 15/1, 36-64.

Ilieva, R. (2000). Exploring Culture in Texts Designed for Use in Adult ESL Classrooms. TESL Canada Journal, 17, 2 , 50-63.

Imada, T. (2012). Cultural narratives of individualism and collectivism: A content analysis of textbook stories in the United States and Japan. Journal of Cross-cultural Psychology, 43, 576-591. 
Kinginger, C. (2004). Alice doesn't live here anymore: Foreign language learning and identity reconstruction. In A. Pavlenko \& A. Blackledge (Eds.), Negotiation of identities in multilingual contexts. Clementon, UK: Multilingual Matters.

Myers-Scotton, C. \& Bernstein, J. (1988). Natural conversation as a model for textbook dialogue. Applied Linguistics, 9, 372-84.

Nguyen, M. Th. Th. (2011). Learning to communicate in a globalized world: To what extent do school textbooks facilitate the development of intercultural pragmatic competence?. RELC Journal, 42, 1, 17-30.

Pearson, E. (1986). Agreement/disagreement: an example of results of discourse analysis applied to the oral English classroom. International Review of Applied Linguistics, 74, 47-61.

Piller, I. (2007). Linguistics and intercultural communication. Language and Linguistics Compass, 1/3, 208-226.

Porecca, K. (1984). Sexism in Current ESL Textbooks. TESOL Quarterly. 18/4.

Ramanathan, V. \& Atkinson, D. (1999). Individualism, academic writing, and ESL writers. Journal of Second Language Writing, 8, 1, 45-75.

Rosaldo, R. (1993). Culture and truth: The remaking of social analysis. Boston, MA: Beacon Press.

Scollon, R. \& Scollon, S. W. (2001). Intercultural Communication: A Discourse Approach. U.K.: Blackwell Publishers, Inc.

Shardakova, M. \& Pavlenko, A. (2004). Identity options in Russian textbooks. Language, Identity and Education, 3(1), $25-46$.

Sheldon, L. (1988). Evaluating ELT Textbooks and Materials. ELT Journal, 42, 2.

Shi-xu, (2006). Beyond competence: A multiculturalist approach to intercultural communication. In K. Bührig, \& J. D. ten Thije (Eds.), Beyond Misunderstanding (313-330). Amsterdam, Philadelphia: John Benjamins Publishing Company.

Siegel, J. (2006). Language ideologies and the education of speakers of marginalized language varieties: Adopting a critical awareness approach. Linguistics and Education, 17, 157-174.

Talburt, S. \& Stewart, M. (1999). What's the subject of SA? Race, gender and "living culture". The Modern language Journal, 91, 163-175.

Ting-Toomey, S. (1998). Communicating across cultures. London: The Guilford Press.

Watkins, L. (2011). The value orientation approach to understanding culture. Annals of Tourism Research,. Retrieved 7 112011 from: www.elsevire.com/locate/atours

Widdowson, H. G. (1990). Aspects of Language Teaching. Oxford: Oxford University Press.

Wierzbicka, A. (2003). Cross-cultural pragmatics: The semantics of human interaction. Mouton de Gruyter: New York

Wolfson, N. (1989). The social dynamics of native and non-native variation in complimenting behavior. In: M. Eisenstein (Ed.). The Dynamic Interlanguage: Empirical Studies in Second Language Variation. New York: Plenum Press, 219-36. 